\title{
Structural Relaxation in the Activated Molten Chloride Electrolytes of Polyvalent Metals
}

\author{
O.M. Shabanov, S.I. Suleymanov, A.O. Magomedova, L.A. Kazieva, F.O. Ismailova \\ Dagestan State University, 367000, Russian Federation, Republic Dagestan, Makhachkala, \\ M. Gadzhieva str., 43-a
}

\author{
*Corresponding Author: O.M. Shabanov, Dagestan State University, 367000, Russian Federation, \\ Republic Dagestan, Makhachkala, M. Gadzhieva str., 43-a
}

\begin{abstract}
The molten salt electrolytes from which the polyvalent active metals are extracted are strongly structured at unusually long distances that increase the energy consumption of the electrowinning cell. Under influence of strong electrical pulses they are transferred to a non-equilibrium state with modification of the structure and intensification of electrochemical properties. The observed regularities in the electrolytes activation are due to stimulated dissociation of complex ions on the simpler and more mobile complex and elementary ions. This is confirmed by the disappearance of characteristic Raman peaks when the melts are activated. During the relaxation process in non-equilibrium melts their electrochemical parameters and Raman peaks are seeking to recover their equilibrium values and pattern. All the observed patterns of the duration and the dynamics of the relaxation in non-equilibrium melts show that we definitely have deal with the structural relaxation in ionic.
\end{abstract}

Keywords: molten electrolytes, activation, non-equilibrium state, structural relaxation

\section{INTRODUCTION}

The structure of equilibrium molten electrolytes, the nature and distribution of structural species in them determine their physicochemical properties, the mechanisms and kinetic pathways that decrease energetic efficiency of metals production technologies [1]. For better understanding the structure of equilibrium molten electrolytes and improving the chemical and electrochemical technologies their structure and physicochemical properties should be studied in a non-equilibrium state. Energy efficiency of electrochemical technologies depends on the Ohm and Faraday voltage drops. These main two factors are dependent on the structure of the molten electrolyte (ME) and the state of metal cations to be extraction: whether they are in the form of elementary ions or they are complexing agents in the structural units- complex ions $M X_{n}^{z-n}(\mathrm{M}=\mathrm{Al}, \mathrm{Mg}, \mathrm{Ce} . . ; \mathrm{X}=\mathrm{F}, \mathrm{Cl}$...) with various stability and lifetimes; they contribute nonequivalent contributions to the mass and charge transfer coefficients. The phenomenon of ions association leads to the deviations from the Nernst-Einstein ratio. The diffraction and spectroscopic studies lead to the conclusion that in the individual molten chlorides of alkaline earth metals, aluminum, cerium and other multivalent metals the long- lived complex ions exist; in them the characteristic signs of intermediate range order is observed [2]. In their mixtures with alkali halides the content of complex ions increases and they become more stable [3]. Electrochemical parameters are defined in the stationary conditions of unperturbed or weakly perturbed state of the molten electrolytes. Meanwhile, these parameters can be changed, and sometimes considerably, in a favorable direction, if to convert the system into a non- equilibrium state under the influence of external forces. One way to achieve this is to impact on the molten system by short electrical pulses of high energy causing the simplifying their structure. The stimulated dissociation of complex ions can be manifested in the increase of the electrical conductivity and the electrolysis current, reducing decomposition potential of the salts, changes in the spectra of the melts. These changes could provide the intensification of the electrochemical technologies process. 
It is known that the Wien effect has served as the experimental proof of the validity of the DebyeHuckel-Onsager theory of electrolyte solutions and is used as the research method in physical chemistry. Prior to our publications, for example $[4,5]$, in the literature has not been articles on the Wien effect in molten salts. We have established the regularity in dependence of conductivity of molten salts on electric field strength (EFS) by analyzing the waveforms of pulsed ( $\mu s$ ) discharges in them. The obtained high-voltage limiting conductivities of individual molten salts obey the NernstEinstein ratio [6].

After completion of high-voltage pulsed discharges in molten electrolytes, their low-voltage conductivity (measured by a conventional AC bridge) turns out to be increased, the electrochemical potentials of the metals turn out to be more positive [6,7], while the characteristic peaks of Raman spectra almost disappear [8], i.e., the "memory" effect is observed in them, which is expressed as "activation» of the melts. These observations were interpreted as a consequence of the stimulated dissociation of complex formations into simpler and elementary ions. The activation of molten electrolytes is followed by the recombination of complex ions during prolonged relaxation processes in them. In this review we present some results in studying the phenomenon of molten electrolytes activation followed by a prolonged structural relaxation in a non-equilibrium state.

\section{EXPERIMENTAL}

The measurements of the EFS - dependence of the conductivity of any electrolyte must be carried out exclusively in the regime of the short time electric pulses in order to avoid a change in the temperature of a sample and introduction of possible electrolysis products into it. To this end in view, we have constructed high-voltage setup for pulsed conductometry. The descriptions of the electric circuit and the measurement cell are presented, in particular, in the publications [9]. The setup involves the digital pulsed memory oscilloscope ASK-8 which records waveforms of attenuated current and voltage during a pulse discharge in the sample. The representative oscillograms (waveforms) without the electric breakdown and at its presence in a molten salt are shown in figures $1 \mathrm{a}$ and $1 \mathrm{~b}$.
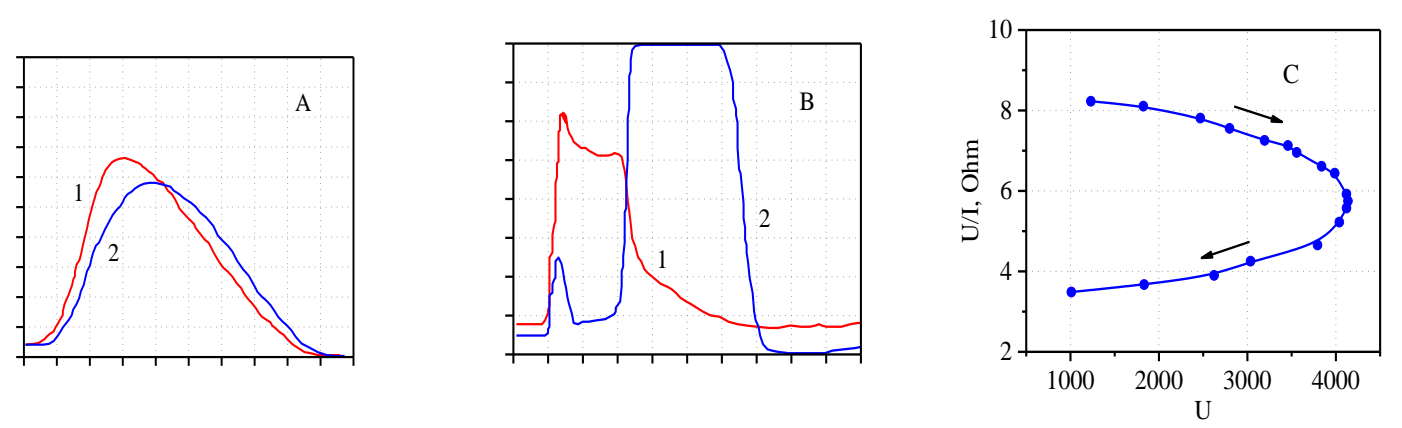

Fig1. a) Characteristic oscillograms of voltage (curve 1) and current (curve 2) of high voltage discharge in molten $\mathrm{MgCl}_{2}$.

The sweep rate is $0.2 \mu \mathrm{s} /$ graduation (axe $\mathrm{x}$ ). The voltage sensitivity (axe y) is $680 \mathrm{~V} /$ graduation, the current sensitivity is $150 \mathrm{~A} /$ graduation; b) The oscillograms of voltage and current of the discharge in an electrolyte at the electric breakdown presence. Voltage drops to zero, and current exceeds the limit of the monitor; c) Dependence U/I as function of U before (curve $\rightarrow$ ) and after (curve $\leftarrow$ ) reaching the current maximum.

The waveforms show that the high voltage pulse duration is several microseconds, the current and voltage of discharge pass through maximums reached in about $1 \mu \mathrm{s}$; after reaching the maximums they fall exponentially (fig.1, a). Full pulse duration excludes introduction of electrolysis products into the electrolyte and it's any significant overheating. This analysis and electroluminescence spectra of molten salts $[5,6,10]$ confirm that regularities observed in behavior of the electrolytes, in strong fields that we used, take place with maintaining the electrolytic nature of the conductance.

To study the phenomenon of the electrolytes activation their conductivity was measured by using ac bridge RLC and the Raman spectra were recorded using a spectrophotometer- both before the 
application of high-voltage pulses on the equilibrium melts and after the pulsed discharges in them were completed. We studied Raman scattering of the molten salts excited by means of the $488 \mathrm{~nm}$ line an argon ion (Coherent) Laser LGN-503. The relaxation dynamics of the non-equilibrium systems was defined by observing the changes in the conductivity and Raman spectra after pulsed discharges having been completed.

\section{EXPERIMENTAL RESUlTS}

\subsection{Wien Effect in Molten Simple Chlorides and Their Mixtures with Potassium Chloride}

Electrical resistance and conductivity of the melts are determined on the basis of the analysis of the waveforms of the current, I, and voltage, U, for the moment of current maximum. Figures 2-5 present the plots of dependence of specific conductivity of molten individual salts and their mixtures with $\mathrm{KCl}$.
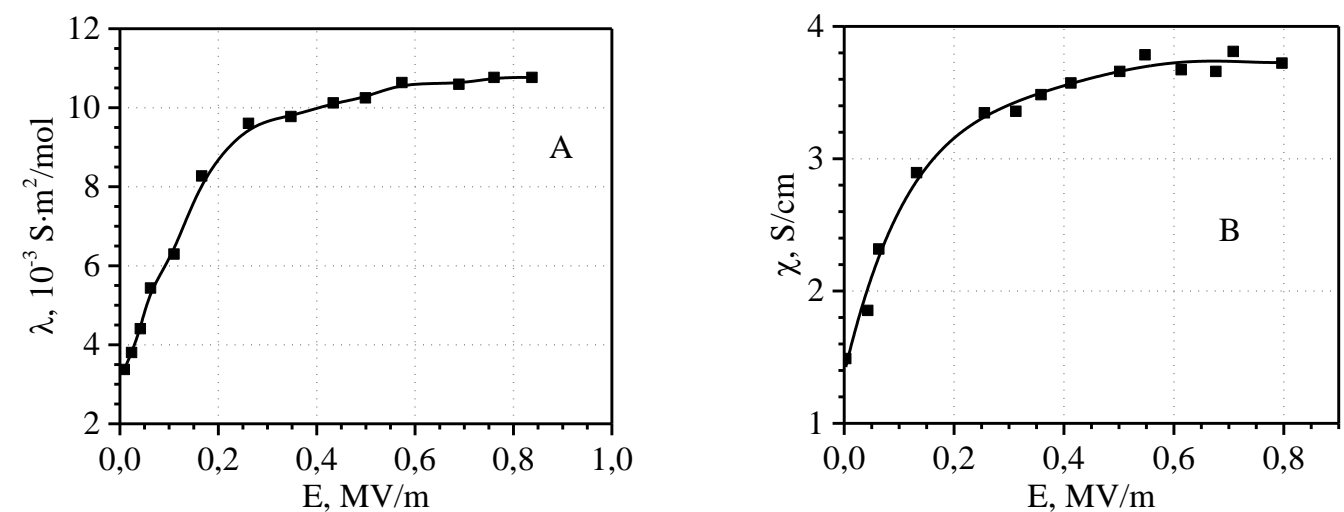

Fig2. Dependence of conductivity of molten $\mathrm{MgCl}_{2}(\mathrm{a})$ and $\mathrm{MgCl}_{2}(0,2)-\mathrm{KCl}(\mathrm{b})$ on the EFS at $1000 \mathrm{~K}$.
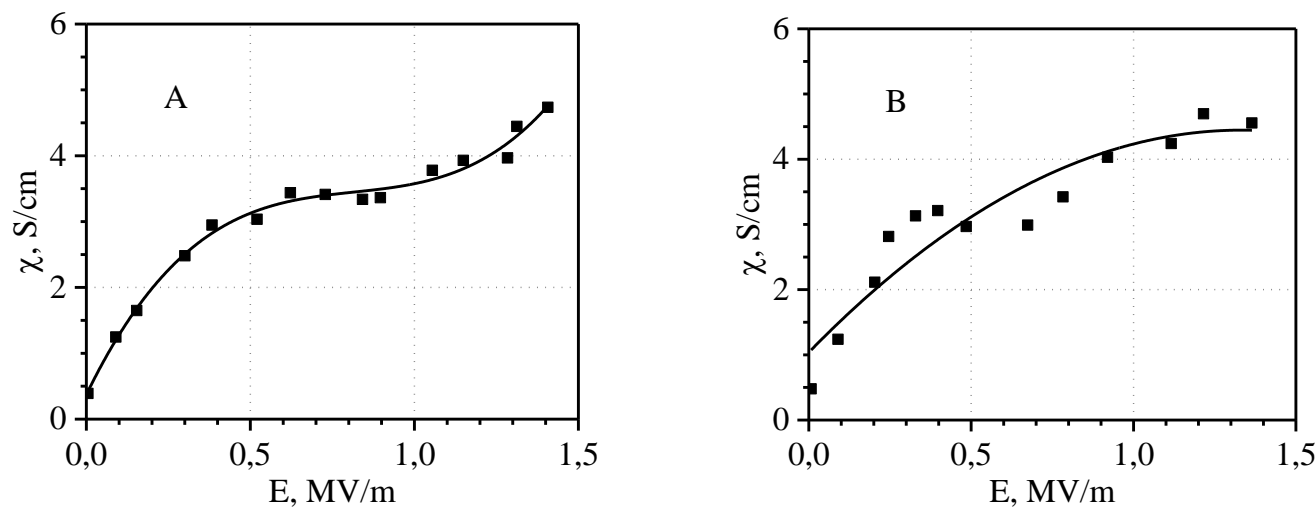

Fig3. Dependence of conductivity of molten $\mathrm{KAlCl}_{4}$ on the EFS at $560 \mathrm{~K}(\mathrm{a})$ at $585 \mathrm{~K}(\mathrm{~b})$.
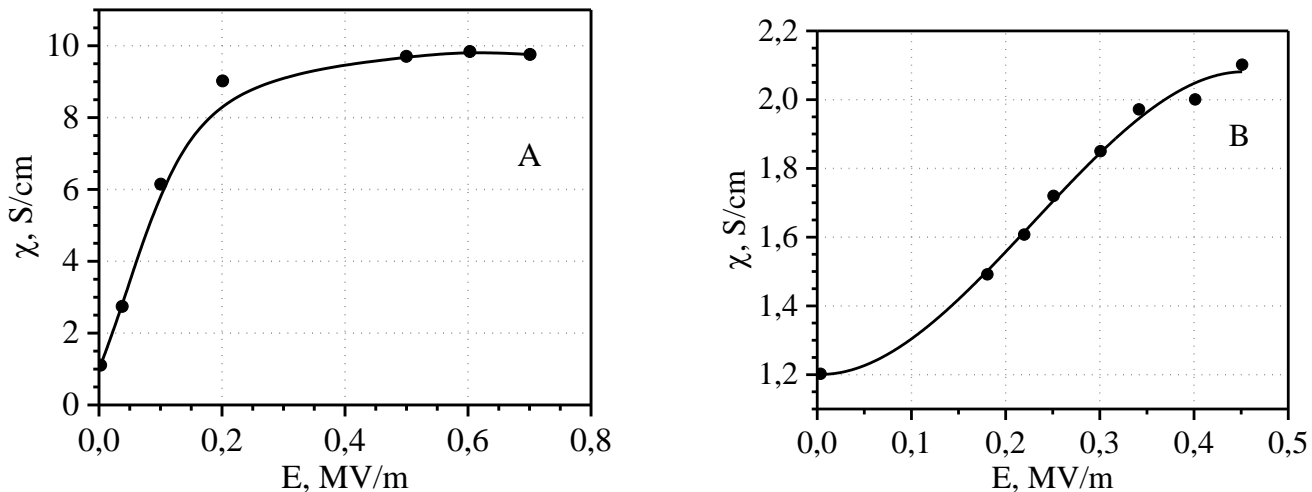

Fig4. Dependence of conductivity of molten $\mathrm{CeCl}_{3}\left(\right.$ a) and $0.2 \mathrm{CeCl}_{3}-\mathrm{KCl}$ (b) melts on the EFS at $1110 \mathrm{~K}$ 

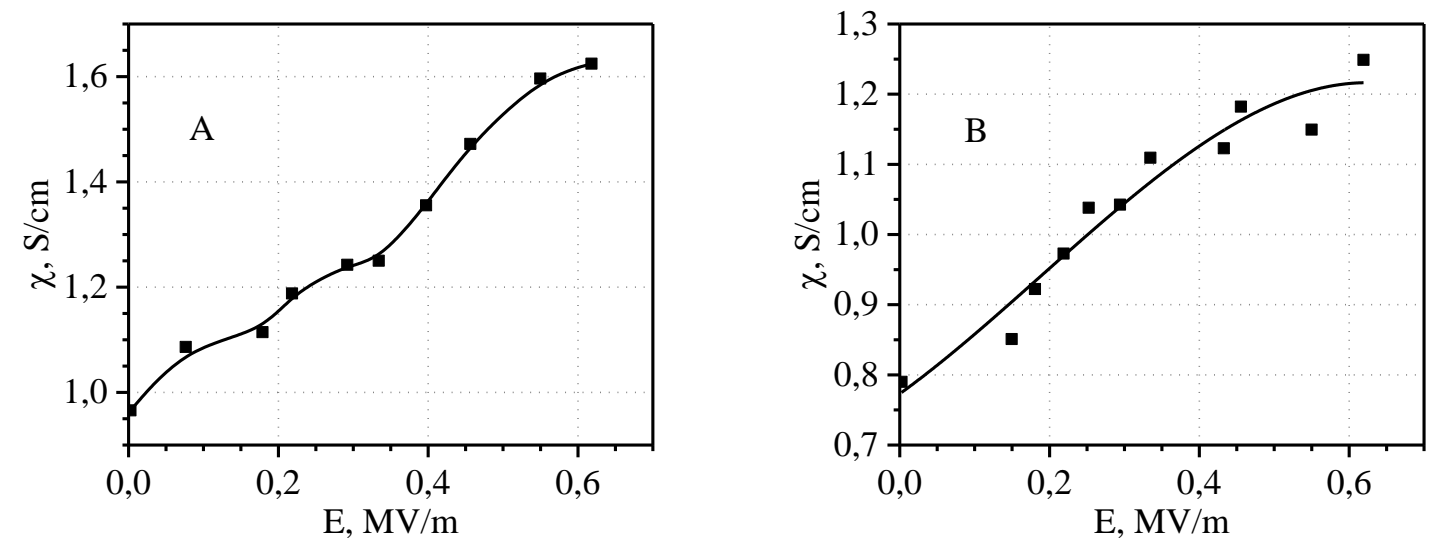

Fig5. Dependence of the conductivity of molten $\mathrm{NdCl}_{3}$ (a) and $0,8 \mathrm{NdCl}_{3}-0,2 \mathrm{KCl}$ (b) on the EFS at $1000^{\circ} \mathrm{C}$.

As seen from Fig. 2-5, the electrical conductivity of molten individual chlorides of polyvalent metals and their mixtures with potassium chloride increases with increasing EFS and tends to the limiting high-voltage values.

\subsection{Electrochemical Potentials of the Metals in Activated Molten Chlorides}

To determine the values of electrochemical potentials of metals in non-equilibrium melts we measured EMF of electrochemical chains of the type $A g, M / M C I n-N a C I-K C I \vdots N a C I-K C I-A g C I / A g$ with 10 mol \% of AgCI and $\mathrm{MCI}_{\mathrm{n}}$ $(\mathrm{M}=\mathrm{Ag}, \mathrm{Mg}, \mathrm{Al}, \mathrm{Zn})$. EMF of the cells were measured initially under equilibrium conditions, and then - after the electrolyte in one of the half-cell being be subjected to the high-voltage pulses action. The observed change in the EMF of the cell is obviously equal to the change in the potential of the metal in the electrolyte, which was transferred to non-equilibrium state. In our experiments, the equilibrium EMF of the silver-lead cell at $943 \mathrm{~K}$ was $320 \mathrm{mV}$. After activation of the silver electrolyte $\mathrm{AgCl}-\mathrm{NaCl}-\mathrm{KCl}$ by series of pulses with the amplitude of voltage $7 \mathrm{kV}$ the, EMF of the element decreased to $274 \mathrm{mV}$. This means that potential of the silver electrode became more positive by 14.4\%. Equilibrium EMF of silver-magnesium cell at $1086 \mathrm{~K}$ was $1932 \mathrm{mV}$. After activation of the magnesium electrolyte $\mathrm{MgCl}_{2}-\mathrm{NaCl}-\mathrm{KCl}$ by series of pulses with the amplitude of voltage of $8 \mathrm{kV}$ EMF of the cell became equal to $1630 \mathrm{mV}$. Consequently, the potential of the magnesium electrode in its activated chloride electrolyte became more positive by $15.6 \%[5,6]$. The results above allow expecting that the decomposition potentials of metal chlorides in non-equilibrium state would be less than in "equilibrium" state. To obtain such experimental data, the study was performed employing linear sweep voltammetry of the magnesium, aluminum and cerium chloride electrolytes.
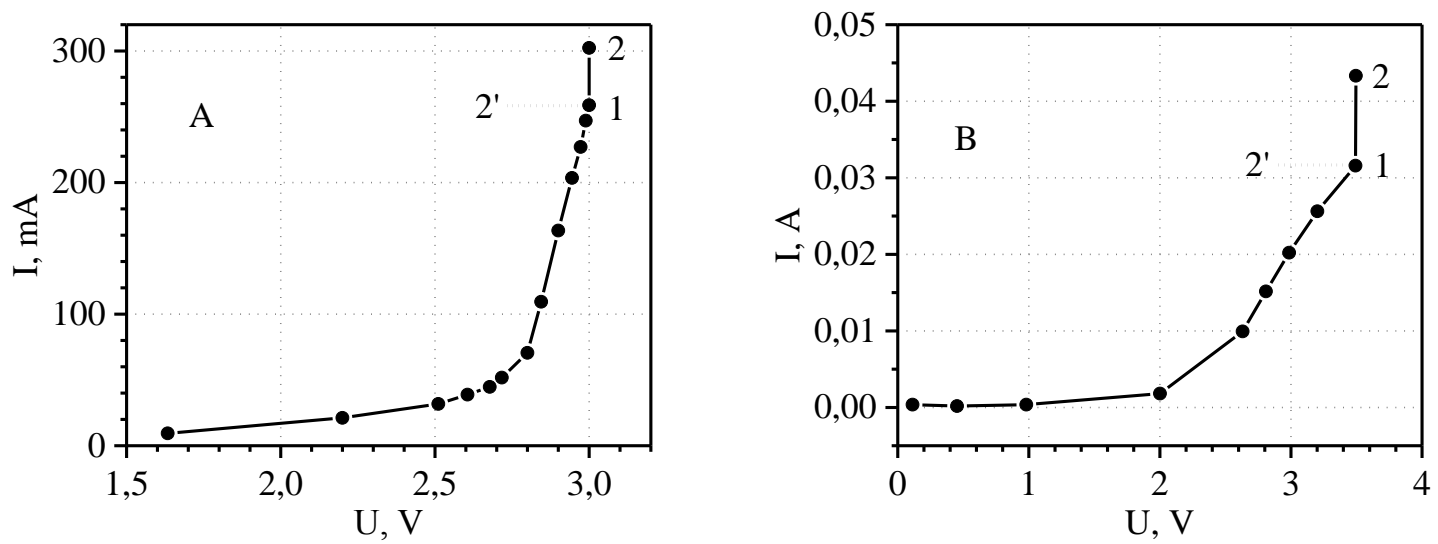

Fig6. Linear sweep voltammograms in $\mathrm{MgCl}_{2}-\mathrm{NaCl}-\mathrm{KCl}(\mathrm{a})$ and $\mathrm{NaCl}-\mathrm{KCl}-\mathrm{CeCl}_{3}(\mathrm{~b})$.

Derived from this dependence the values of the decomposition potentials of $\mathrm{MgCl}_{2}$ and $\mathrm{CeCl}_{3}$ in non perturbed melts were found equal to $2.73 \mathrm{~V}$ and $2.1 \mathrm{~V}$, respectively, in good agreement with the 
literature. After exposure to the molten electrolyte of 10 pulses with voltage amplitude of $6 \mathrm{kV}$, electrolyze current is increased by more than $20 \%$, while the electrolysis voltage was maintained equal to the initial value (points 1-2). While maintaining the same initial value of the electrolysis current, the voltage on the cell is correspondingly reduced (points $1^{\prime}-2^{\prime}$ ). This means that the decomposition potentials of the $\mathrm{MCl}_{\mathrm{n}}$ salts decrease upon activation of their electrolytes. A similar analysis was performed and similar results have been found for the electrolysis of aluminum and neodim chloride electrolytes. The degree of electrolyze intensification rises with increasing number of pulses and their voltage amplitude, and tends to the saturation.

\subsection{Intensification of Conductivity of Molten Metal Chloride Electrolytes}

An analysis of the oscillograms (waveforms) in Figure 1,c shows that U/I for full discharge sweep at $\mathrm{U} \rightarrow 0$ in the lower curve (after reaching the maximum current) is lower than the initial value (at $\tau$ $\rightarrow 0, \mathrm{U} \rightarrow 0$ ) determined from the upper curve. In our experiments on Wien effect, every next voltage pulse was applied to an electrolyte only after the initial low-voltage conductivity was restored. This mined that the electrical conductivity of a sample measured by a conventional ac bridge increases as a result on subjecting it to a large electric pulse electric field; that is, the memory" effect is observed. The activation degree is expressed as

$\Delta \chi / \chi(0)=[\chi(\tau)-\chi(0)] / \chi(0)$, where $\chi(0)$ is the initial (low-voltage) conductivity and $\chi(\tau)$ is the lowvoltage conductivity at time $\tau=0$ after the end of a high-voltage pulse. The activation degree of conductivity also rises with increasing number of pulses and their voltage amplitude, and tends to the saturation. In Figure 7, as examples, these dependences are presented for a magnesium electrolyte
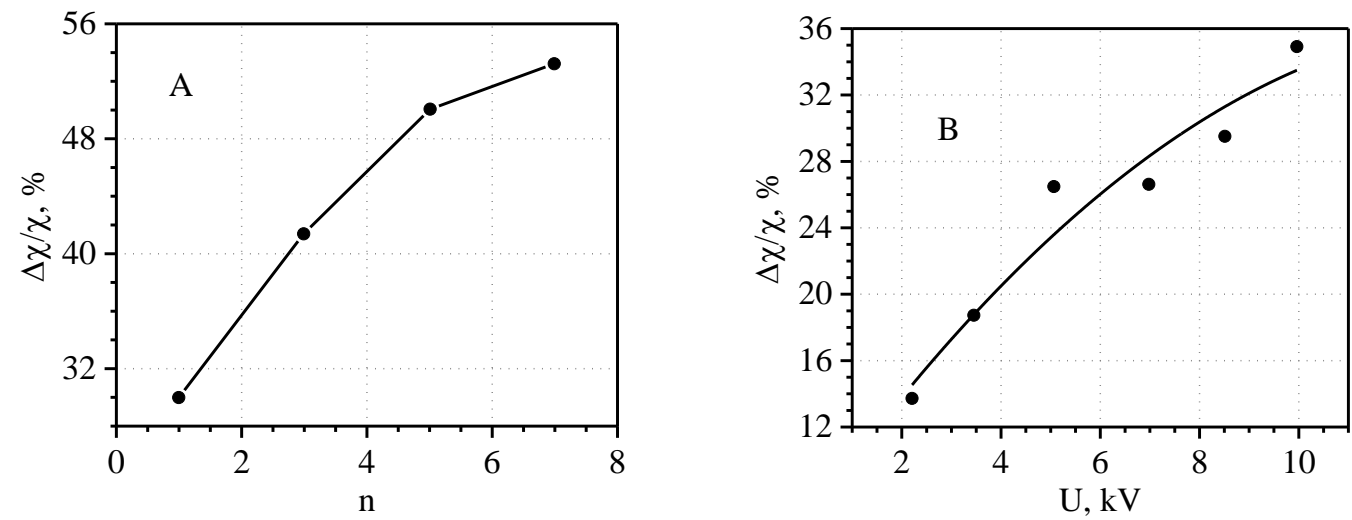

Fig7. Dependence of relative increase in conductivity $\Delta \chi / \chi(0)$ of the molten mixture $0,2 \mathrm{MgCl}_{2}-0,8 \mathrm{KCl}$ on the number of activating pulses in series with the voltage amplitude of $8.5 \mathrm{kV}$ (a) and on the voltage amplitude of single pulses (b) at $983 \mathrm{~K}$.

Similar results were obtained for other compositions of molten mixtures [7-15]. The results obtained in Sections 3.1 and 3.3 are collected in Table 1.

Table1. Wien effect and activation degree of some molten chloride electrolytes

\begin{tabular}{|c|c|c|c|c|c|}
\hline Melt & $\mathrm{T}, \mathrm{K}$ & $\begin{array}{l}\chi(0), \\
S / c m\end{array}$ & $\chi^{0}, S / c m$ & $\begin{array}{l}\frac{\Delta \chi}{\chi(0)}, \% \\
\text { (Wien effect) }\end{array}$ & $\frac{\Delta \chi}{\chi(0)}, \%$ \\
\hline $\mathrm{MgCl}_{2}$ & 1000 & 1.05 & 3.48 & 265 & 14 \\
\hline $0.8 \mathrm{KCl}-\mathrm{MgCl}_{2}$ & 980 & 1.40 & 3.72 & 166 & 35 \\
\hline $\mathrm{KAlCl}_{4}$ & 560 & 0.50 & 4.50 & 800 & 30 \\
\hline $\mathrm{CeCl}_{3}$ & 1110 & 1.10 & 9.70 & 782 & 17 \\
\hline $0.8 \mathrm{KCl}-\mathrm{CeCl}_{3}$ & 1110 & 1.20 & 2.12 & 77 & 32 \\
\hline $\mathrm{NdCl}_{3}$ & 1082 & 0,95 & 1.65 & 79 & 15 \\
\hline $\mathrm{NdCl}_{3}-\mathrm{KCl}$ & 1082 & 0.79 & 1.25 & 58 & 18 \\
\hline
\end{tabular}

\subsection{Relaxation in Activated Molten Chloride Electrolytes}

The above values relate to the degree of activation at the time $t=0$ after the completion of the pulses. In this section, the regularities of the change in the degree of activation 
$\Delta \chi / \chi(0)=[\chi(t)-\chi(0)] / \chi(0)$ in time are described; here $\chi(t)$ is the low-voltage conductivity of the melt at time $\mathrm{t}$ after the pulse action completion.

The activated molten electrolytes are in the non equilibrium state with the increased conductivity. These systems tend to the equilibrium state with the restoration of the equilibrium values of the electrical conductivity at unchanged temperature; in these systems the relaxation processes take place. The figures below show some examples of the relaxation curves in some non-equilibrium molten electrolytes.
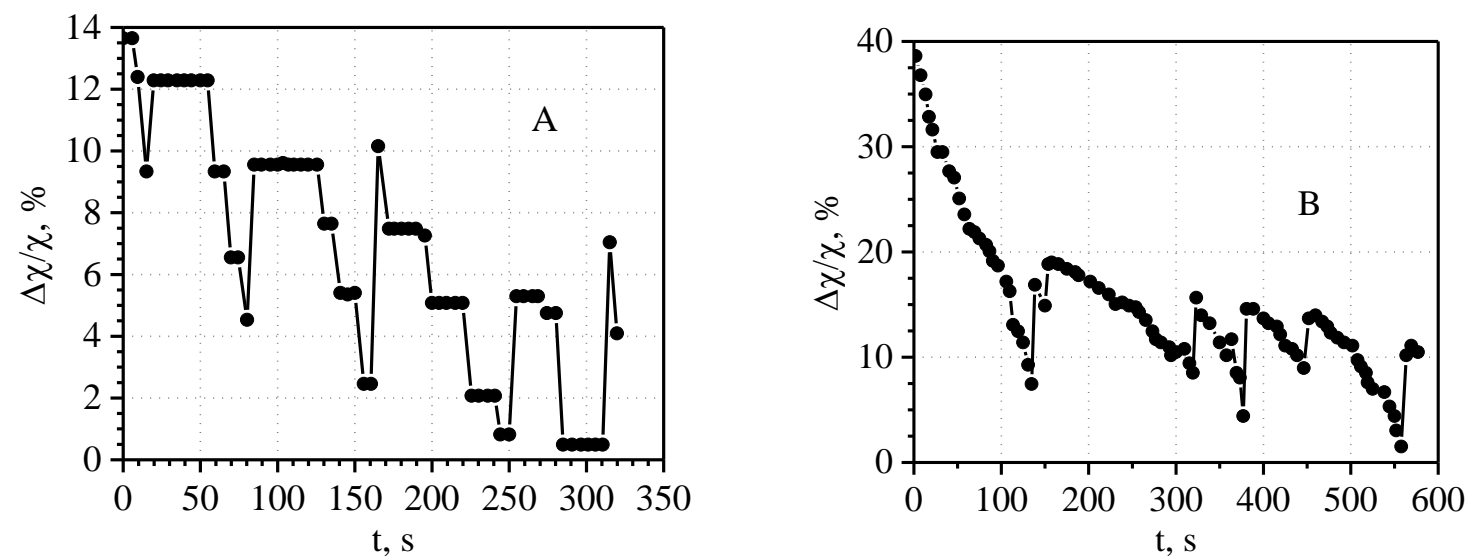

Fig8. Change of the relative values $\Delta \chi / \chi(0), \%$ in time in the molten mixture $\mathrm{MgCl}_{2}(0,2)-\mathrm{KCl}$ A) activated by one pulse of voltage amplitude $2,2 \mathrm{kV}$, and B) activated by 3 pulses of the amplitude $10 \mathrm{kV} . \mathrm{T}=983 \mathrm{~K}$
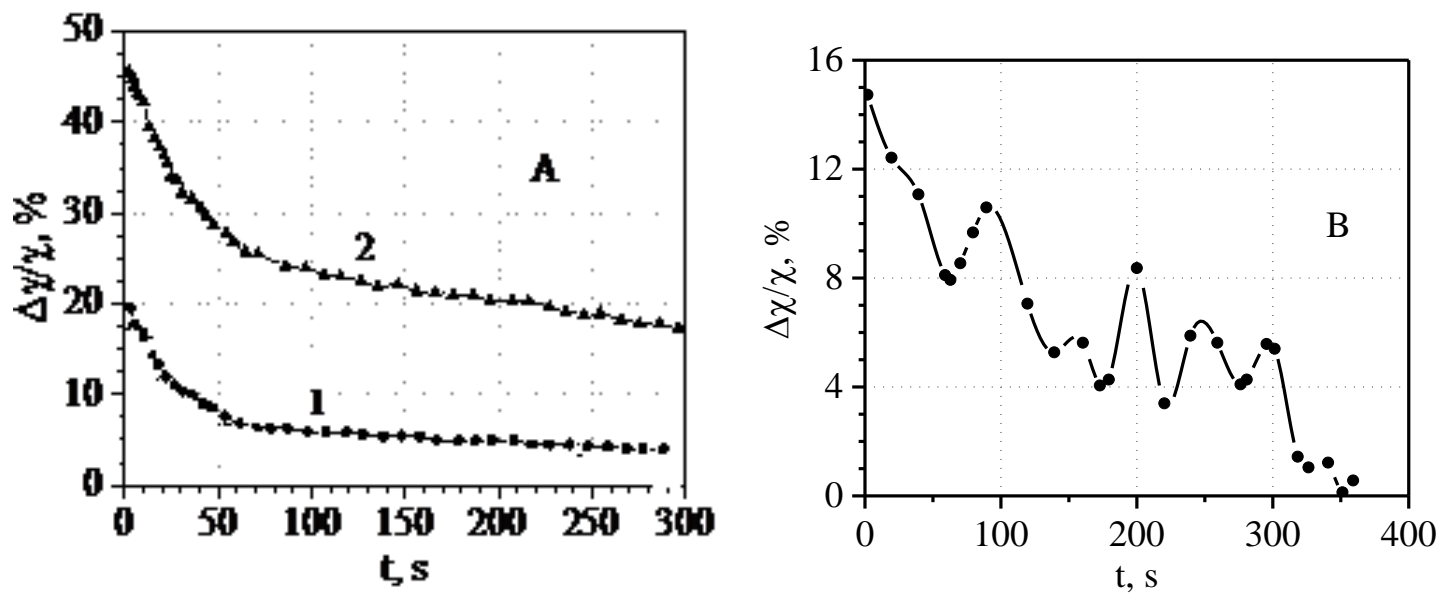

Fig9. The relaxation curves in A) the molten $\mathrm{KAlCl}_{4}$ activated by single pulses of voltage amplitude: 1) 8,6 $\mathrm{kV}$ and 2) 13,0 $\mathrm{kV}$ at $\mathrm{T}=558 \mathrm{~K}(\mathrm{~A})$ and $\mathrm{B}$ ) the molten $\mathrm{NdCl}_{3}-0,2 \mathrm{KCl}$ activated by single pulse of the voltage amplitude $5 \mathrm{kV}$ at $1082 \mathrm{~K}$.

It is seen from Figs. $7-9$ that the degree of electrical conductivity activation $\Delta \chi / \chi(0)$ reaches $45 \%$, the increased electrical conductivity of the electrolytes in the non- equilibrium state decreases in the time and tends to the initial (equilibrium) values.

\subsection{Changes in Raman Spectra of Molten $\mathrm{Mgcl}_{2}$ And $\mathrm{Zncl}_{2}$}

In the beginning, we have reproduced the known literary characteristic Raman spectra of equilibrium molten salts $\mathrm{MgCl}_{2}$ and $\mathrm{ZnCl}_{2}$. Then we recorded the spectra of the melts after them exposing to microsecond high voltage pulses. The spectra for the molten $\mathrm{MgCl}_{2}$ at $973 \mathrm{~K}, \mathrm{ZnCl}_{2}$ at $624 \mathrm{~K}$, normalized using the total polarized scattered intensity, are shown in fig.10. The Raleigh background signals were removed from all spectra via standard baseline subtraction and all spectra are normalized into a unit area. The obtained spectra of individual equilibrium molten salts are in good agreement with literature data. 

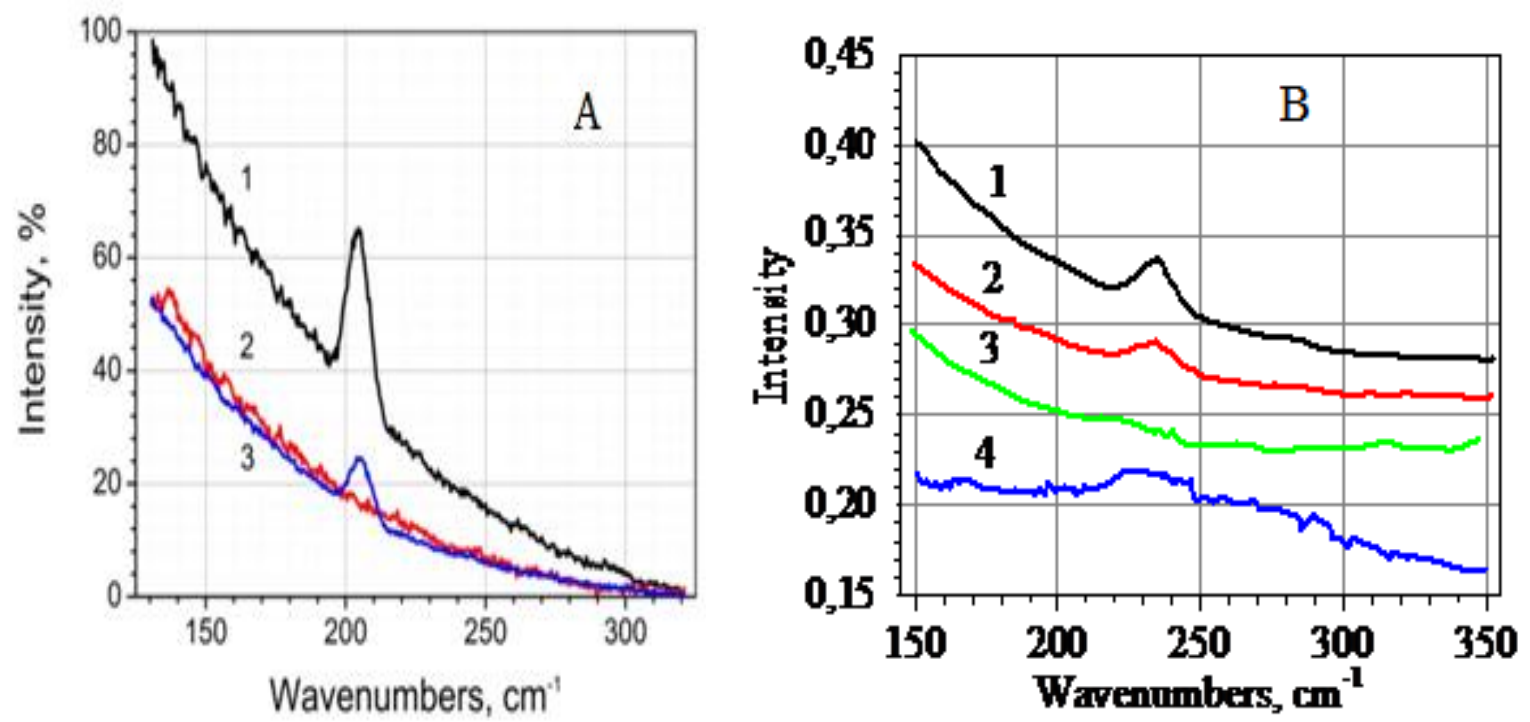

Fig10.A) Raman spectra of equilibrium molten $\mathrm{MgCl}_{2}$ (curve 1) and of its melt subjected to 3 electric pulses of voltage amplitude of $8 \mathrm{kV}$ (curve 2) at $973 \mathrm{~K}$. The curve 3 represents the Raman spectra of the non-equilibrium melt in the relaxation processes 10 minutes after activation.

B) Raman spectra of solid $\mathrm{ZnCl}_{2}$ (curve 1), of its equilibrium melt at $624 \mathrm{~K}$ (curve 2) and of the melt subjected to 5 electric pulses of voltage amplitude of $8 \mathrm{kV}$ (curve 3) at $624 \mathrm{~K}$. The curve 4 represents the Raman spectrum of the non-equilibrium melt in the relaxation processes 10 minutes after activation.

As a result of previous pulses influence, the spectral peaks disappear almost completely due to the melts transition to a non-equilibrium state. In the relaxation processes in non-equilibrium melts the Raman spectra take several minutes to be re-established.

\section{DISCUSSION}

Structure and electrochemical properties of molten electrolytes are studied mainly in their equilibrium or slightly non-equilibrium states; they are determined by the nature and distribution of structural species in them. For the molten alkali halides [16] and alkali earth halides [17], the structural autocomplex model has been a priori assumed according to which the molten salts may be considered as the mixture of $M X_{4}^{Z-4}$ anions and $M^{Z+}$ cations as the structural elements. Later, as a result of the development of spectroscopic methods, it was proved that autocomplexes in individual molten metal halides are not a priory abstraction but can quite reliably be fixed in Raman spectra [18]. Their Raman spectra indicate presence in the molten magnesium electrolyte of a discrete tetrahedral $\mathrm{MgCl}_{4}^{2-}$ species in equilibrium with complex ions $\mathrm{MgCl}^{-}, \mathrm{MgCI}_{3}^{-}, \mathrm{MgCl}_{4}^{2-}, \mathrm{Mg}_{2} \mathrm{CI}_{6}^{2-}, \mathrm{Mg}_{2} \mathrm{Cl}_{7}^{3-}$ [19]. In the molten aluminum chloride electrolytes complexions $\mathrm{AlCl}_{4}^{-}$and $\mathrm{Al}_{2} \mathrm{Cl}_{7}^{-}$are identified [20]. In addition to binuclear forms in the melts does not excluded the probability of the existence of higher polymeric forms of formula $\mathrm{Al}_{n} \mathrm{Cl}_{3 n+1}$. In the chloride electrolytes of rare-earth metals (Ln) the isolated octahedral $\mathrm{LnCl}_{6}^{3-}$ ions are indefinitely formed and form loose network-clusters composed of edge bridged octahedrons connected to each other [21]. The observed behavior of the molten electrolytes in the Wien effect and the activation phenomenon can be understood on the basis of stimulated dissociation of the complex ions under action of strong electric pulses. The system tends to the equilibrium state, to reestablish its equilibrium characteristic structural species diversity and their distribution. Performing a Fourier analysis of the time series for the relaxation in non-equilibrium molten $\mathrm{MgCl}_{2}-\mathrm{KCl}$ leads to the conclusion about realization of a quasi-periodic regime of oscillation and about deterministic chaos; the dimensionality of a phase space corresponds to five [22]. This phase space corresponds to the five structural spaces in this system above; from the fig. 8 we see that the number of failures of the conductivity from the steps and the number of jumps are also equal to five. The observed structural relaxation in non-equilibrium systems exhibit all the signs of the self- organization and it is obvious that entropy is decreased in the recombination reactions of the structural units - complex ions of different symmetry. 


\section{CONClusions}

The molten chloride electrolytes of polyvalent metals subjected to the high-voltage microsecond pulses manifest the activation phenomenon and the transition to non-equilibrium state with increased electrical conductivity, disappeared characteristic Raman peaks and prolonged structural relaxation.

\section{CONFLICT OF INTEREST}

The authors have no conflicts of interests.

\section{ACKNOWLEDGEMENT}

This work was supported by Russian Foundation for Basic Research project

№ 15-08-00559

\section{REFERENCES}

[1] S.-Y. Yoon, Flint J.H., Kipouros and Sadowy D.R. J. Light Metals, 2001, vol.1, p. 111-117.

[2] Salanne M, Simon C, Turq P. and Madden P. A. J. Phys. Condens. Matter., 2008, vol. 20, p. 332101332106.

[3] Sakai K., Nakamura T., Umesaki N., Iwamoto N. Phys. and Chem. Liqu. 1984, vol. 14, p. 67-73.

[4] Shabanov O.M. Melts (Russian), 1987, № 5, 66-75.

[5] Shabanov O.M., Gadzhiev S.M., Magomedova A.O. Dzhamalova S.A. Chem. Phys. Letters. 2003, vol. $380,352-358$.

[6] Shabanov O.M., Ismailova F.O., Maksumova D.G., Gadzhiev S.M., Magomedova A.O. Russian J. Electrochem., 2006, vol.42, p. 986-989.cм 13

[7] Shabanov O.M., Iskakova A.A., Kachaev R.T. Melts (Russia), 2011, № 2, 249-257.

[8] Shabanov O.M., Kachaev P.T., Suleymanov S.I. Advanc. Mater. Research, 2013, vol. 718-720, p. 146152.

[9] Gadzhiev S.M., Shabanov O.M., Magomedova A.O., Dzhamalova S.A. Russian Journal of Electrochemistry, 2003, vol. 39 (4), 386-391.

[10] Shabanov O.M. Activation of molten and solid electrolytes. LAP LAMBERT Acad. Publ. 2013. 123 p. (ISSN: 987-3-659-38494-3).

[11] Shabanov O.M., Gadzhiev S.M., Iskakova A.A., Kachaev R.T.,Magomedova A.O., Suleymanov S. I. Russian J. Electrochem., 2011, vol. 47, 2, 221-224.

[12] Shabanov O.M., Iskakova A.A., Kachaev R.T. Melts (Russia), 2011, № 2, 249-257.

[13] Shabanov O.M., Suleymanov S.I.,Kazieva L.A., Magomedova A.O. Russian J. Chem and Chem. Technol., 2014. vol. 57, p. 52-56.

[14] Shabanov O M, Kazieva L A, Kachaev R T, Magomedova A O, and Suleimanov S I 2015 Russian Metallurgy (Metally) 8654

[15] O M Shabanov, S I Suleymanov and A O Magomedova. IOP Conf. Ser.:Sci. Eng. 168(2017) 012006.

[16] Smirnov M.V. Shabanov O.M. and Khaimenov A.P.. Electrochemiya (USSR), 1966, v.2, 1240-1248.

[17] Pelton A.B. Canad. J. Chem., 1971, vol.49, p. 3919-3934.

[18] Papatheodorou G., Dracooulos VChem. Chem. Phys. Lett., 1995, vol. 241, p.345-350.

[19] Broocker M.H. and Huang C.H. Can. J. Chem., 1980, v. 58, p.168-179.

[20] Rytter, E., Øye, H. A., Cyvin, S. J., Cyvin, B. N., \& Klæboe, P. J. Inorg. and Nuclear Chem., 1973, vol. 35, p.1185-192.

[21] Takeshi U., Toshiyukii F. Z. Anorgan. Allgem. Chem., 2013, v.639, p. 765-773.

[22] Shabanov O.M., Magomedbekov U.G., Maksumova D.G., Ismailova F.O., Gadzhiev S.M. Melts (Russian), 2006, № 2, p.39-46.

Citation: O.M. Shabanov et al. (2017). Structural Relaxation in the Activated Molten Chloride Electrolytes of Polyvalent Metals, International Journal of Mining Science (IJMS), 3(3), pp.1-8, DOI: http://dx.doi.org/ 10.20431/2454-9460.0303001.

Copyright: (C) 2017 O.M. Shabanov. This is an open-access article distributed under the terms of the Creative Commons Attribution License, which permits unrestricted use, distribution, and reproduction in any medium, provided the original author and source are credited 